\title{
Education and Mental Health in the Pandemic
}

\author{
Cortes $\mathbf{R}^{*}$ \\ University of Cundinamarca, Colombia
}

\section{Editorial}

The situation generated by the pandemic caused by SARS-CoV-2 led to changes in people's lives and, in the psychological field, alterations in mental health. The lack of socialization due to quarantine, deaths from the disease, associated news about the pandemic, a new workload of activities for education and jobs, among others, have brought about consequences such as anxiety, stress problems, family and bonding difficulties, as well as unresolved grief.

What has been described above has led to the adaptation of daily, work and educational activities of people in various parts of the world. In the special case of teachers and students, adapting to acquire skills in technology and digital media to be able to carry out class sessions in a more didactic way to keep the students engaged in the subject. However, the pandemic is not over, despite vaccination initiatives, and there are still social restrictions to safeguard the physical health of individuals, as we reach normality.

In developing countries, the social and economic gap can be observed, which is manifested in the difficulty that students have in accessing technological tools and network accessibility, which leads to the recursive use of the inefficient devices to attend lessons. Although institutions and governments have provided solutions that allow this access, psychological support is also necessary, which allows them to cope with associated frustration.

Regarding the educational environment, which is the focus in this article, I would like to recommend, as a psychologist and teacher, some aspects that can assist in class sessions to run smoothly. Most importantly, here is advice which would maintain the motivation of the students and strengthen their pedagogical and academic relationships.

1. Start the sessions by inquiring about the situation of the students and their families, which can create an atmosphere of empathy and trust in the class. For students this is a signifi- cant gesture of interest on the part of the teacher. However, if there is evidence of a case that involves a psychological problem, the teacher must seek assistance from a competent professional.

2. Although students await explanations from their teachers on the topics of the sessions, it is necessary to invite debate and argumentative dialogue, which will lead to greater participation and interaction from the students.

3. Although it is well known, that the use of technological resources can support and make sessions more practical. In this sense, there are pages and web applications that can be useful as tools associated with the realization of virtual laboratories, virtual visits to museums for history or language classes, interactive videos, as well as gamification in the classroom.

4. A recommendation is to avoid stressing students with an encumbering workload, as done with traditional schooling, but to instead fully engage students during class sessions. In this case, an alternative is seek the integration of projects and work with other teachers to create cooperative proposals.

5. Generate activities with resources that students enjoy and are more familiarized with such as: social networks, blogs, and web content to support their work. These tools should be used for the dissemination of academic and scientific information.

6. Recognizing the students' work can make them even more interested in the class. Teachers can show the results of their students' work, with their consent, by publishing them in the internal media of the institution as well as in local newspapers or the websites of the educational institution itself.

\begin{tabular}{|l|l|}
\hline \hline Quick Response Code: & *Corresponding author: Rafael Leonardo Cortes Lugo, Psychology program of the University \\
of Cundinamarca, Colombia \\
Received: 27 May, 2021 \\
Citation: Cortes R. Education and Mental Health in the Pandemic. J Psych Sci Res. 2021;1(3):1- \\
\hline
\end{tabular}


7. Teachers should be flexible at planning their classes and include, in the educational curriculum, current topics that interest students and promote their participation. This will result in an opportunity for them to make their own discoveries, which can be significant in the learning_process as well as in the development of their own ideas and their personality.

8. The joint development of informative material between teachers and students can be an opportunity for a cooperative learning experience. In this case, the student can obtain skills and competencies indicated by their teachers, in turn understanding the need and importance of why academic and research content is created.

9. Promote the student participation in showcasing their work; this allows to view projects and work done in class. In this way, the student is invited to believe in himself and face spaces where he has to socialize with other people in academic contexts.
In general terms, it is also possible that the academic environment and specifically, the classroom, or the virtual space for the session, also becomes a therapeutic environment where both teacher and student share an academic relationship. This should be transformed into a constructive experience to learn from each other in a space that adheres to respect and responsibility, while promoting trust.

\section{Acknowledgments}

To my family, my parents' and my students.

\section{Funding}

None.

\section{Conflicts of Interest}

Author declares that there is no conflict of interest. 